\title{
6A.4 IMPACT OF A WARM OCEAN EDDY'S CIRCULATION ON HURRICANE-INDUCED SEA SURFACE COOLING WITH IMPLICATIONS FOR HURRICANE INTENSITY
}

\author{
Richard M. Yablonsky* and Isaac Ginis \\ University of Rhode Island, Narragansett, Rhode Island
}

\section{INTRODUCTION}

Evaporation from the sea surface, primarily within a hurricane's core, provides the heat energy required to intensify and maintain the storm (e.g. Cione and Uhlhorn 2003, Emanuel 2003, and references therein). If the sea surface temperature (SST) decreases within the storm core, so does the heat energy available to the storm. Generally, in the deep ocean, SST cooling within the storm core occurs primarily because the storm's surface winds impose a wind stress on the upper ocean, and the resulting ocean current shear generates turbulent mixing and entrainment of cooler water into the upper oceanic mixed layer from below (e.g. Ginis 1995, 2002, and references therein). In addition, for slowmoving hurricanes especially, the storm's cyclonic wind stress generates upper-ocean current divergence and upwelling, which in turn may contribute significantly to storm-core SST cooling (Price 1981; Yablonsky and Ginis 2009, hereafter YG09). Evaporative heat flux to the atmosphere, while vital to the hurricane, contributes far less than mixing/entrainment to storm-core SST cooling in the deep ocean (Price 1981; Shen and Ginis 2003; D'Asaro et al. 2007).

Since the SST in advance of a hurricane cannot account for the storm-induced SST cooling, upper oceanic heat content $(\mathrm{OHC}$, also known as tropical cyclone or hurricane heat potential) ahead of the storm has become more widely accepted than pre-storm SST as a measure of the ocean energy available to the hurricane for future storm intensification and/or maintenance (e.g. Mainelli et al. 2008; Shay et al. 2000). OHC, originally defined by Leipper and Volgenau (1972), can be calculated as follows:

$$
O H C=\int_{0}^{d 26} \rho c_{p}\left(T\left({ }^{\circ} \mathrm{C}\right)-26\right) d z
$$

where $d 26$ is the depth of the $26^{\circ} \mathrm{C}$ isotherm, $\rho$ is the seawater density, $c_{p}$ is specific heat at constant pressure, $T$ is the ocean temperature, and $d z$ is the change in depth. While certainly a valuable quantity, the utility of $\mathrm{OHC}$ as a measure of future heat available within a hurricane's core may be limited by its inability to account for nonlocal processes, as discussed below.

Another potential mechanism for storm-core SST cooling is horizontal advection of the storm's cold wake when preexisting ocean currents are oriented in the same direction as the storm track. This situation can occur when a warm ocean eddy, also known as a warm core ring (WCR), is located to the right (left) of the storm track in the Northern (Southern) Hemisphere because a

* Corresponding author address: Richard M. Yablonsky, Univ. of Rhode Island, Graduate School of Oceanography, 215 South Ferry Road, Narragansett, RI 02882; e-mail: ryablonsky@gso.uri.edu.
WCR is an anticyclone in approximately geostrophic balance, so it circulates clockwise (counterclockwise) in the Northern (Southern) Hemisphere. For brevity, only the Northern Hemisphere case will be considered from this point forward. Many previous modeling and observational studies have investigated the interaction between a hurricane (or equivalently, a typhoon or cyclone) and a WCR, yet none of these studies consider a scenario whereby a WCR may be responsible for weakening a hurricane. In fact, Lin et al. (2008) suggest that WCRs can be treated as "boosters", whereby WCRs are always favorable features for hurricane intensification.

The primary goal of this study is to assess whether or not advection due to a WCR can play a significant role in storm-core SST cooling; if so, a WCR could potentially have the opposite effect on storm-core SST cooling and subsequent hurricane intensity change than would be predicted by OHC alone. In addition, a WCR's circulation may contribute to enhanced surface current divergence, thereby increasing the magnitude of upwelling. Towards this end, a three-dimensional (3D) ocean model is used to test the impact of a WCR on hurricane-induced sea surface cooling.

\section{EXPERIMENTAL DESIGN}

The 3D experiments in this study are performed using a version of the Princeton Ocean Model (POM; Blumberg and Mellor 1987; Mellor 2004) that is similar to the version used in the operational GFDL/URI coupled hurricane-ocean prediction system (hereafter GFDL model) for the Atlantic basin (Bender et al. 2007) and is identical to the version used in YG09. Additionally, one-dimensional (1D) experiments are performed using this same version of POM, except the advection and pressure gradient terms are removed so that at each grid point, there is no interaction amongst surrounding grid points in the horizontal, as in YG09. For simplicity, horizontal diffusion terms are not removed, but tests show the impact of these terms is negligible. This 1D simplification is consistent with the $1 D$ version currently used in the GFDL model for the eastern Pacific basin (Bender et al. 2007). For all experiments, the ocean grid spans from $108.5^{\circ} \mathrm{W}$ to $60^{\circ} \mathrm{W}$ longitude and from $10^{\circ} \mathrm{N}$ to $47.5^{\circ} \mathrm{N}$ latitude. Unlike the operational GFDL model, the ocean grid is set on an f-plane, where the earth's rotation rate and the longitudinal grid spacing assume constant latitude of $22.4^{\circ} \mathrm{N}$. There are $508(449)$ grid points in the $\mathrm{x}-(\mathrm{y}-)$ direction, yielding a horizontal grid spacing of 9.8 (9.3) $\mathrm{km}$ in the $\mathrm{x}-(\mathrm{y}-)$ direction. The entire domain is assumed to be a 2500-m deep ocean (no land or bathymetry), and the 23 half-sigma levels are placed at the following depths: $2.5,7.5,12.5,17.5,22.5,27.5,32.5,40,47.5$, 
$55,67.5,87.5,125,187.5,275,387.5,550,775,1050$, $1400,1800,225$, and $2500 \mathrm{~m}$.

\subsection{Control Experiments}

In the control experiments (CTRL), the ocean is initialized with a horizontally-homogeneous temperature (T) and salinity (S) profile. These profiles are based on the $0-2500-m$ portion of the Generalized Digital Environmental Model (GDEM) climatological profile in the Gulf of Mexico Common Water during the month of September (Teague et al. 1990); the upper $150 \mathrm{~m}$ of the $\mathrm{T}$ profile is shown (Fig. 1a). Once $\mathrm{T}$ and $\mathrm{S}$ are defined on the POM grid, hurricane wind stress is applied (Fig. $1 \mathrm{~b})$, with the storm center initially located at $\left(22.4^{\circ} \mathrm{N}\right.$, $\left.71.7^{\circ} \mathrm{W}\right)$. The wind stress distribution is based on the wind field derived from an analytic model of the wind and pressure profiles in hurricanes (Holland 1980), where in this case the central pressure, environmental pressure, maximum wind speed, and radius of maximum winds (RMW) are $950 \mathrm{hPa}, 1013 \mathrm{hPa}, 55 \mathrm{~m} \mathrm{~s}^{-}$ 1 , and $55 \mathrm{~km}$, respectively. Asymmetry is included in this otherwise axisymmetric wind field by adding half of the storm translation speed, as in Price (1981). Once the wind field is calculated, the wind stress magnitude ( $\mathrm{\tau}$ ) is calculated using the bulk formula, $\tau=\rho C_{D} U_{10}{ }^{2}$, where density $\rho=1.28 \mathrm{~kg} \mathrm{~m}^{-3}$ and the drag coefficient $\left(C_{D}\right)$ is calculated as an empirical function of the $10-\mathrm{m}$ wind speed $\left(\cup_{10}\right)$, similar to Moon et al. (2007) but modified to decrease $C_{D}$ at high wind speeds to be more consistent with observations, as suggested by Tung (2008). This wind stress field translates westward with a constant, prescribed speed of either $0.5^{\circ}$ longitude per 6 hours $\left(2.4 \mathrm{~m} \mathrm{~s}^{-1}\right)$ or $1.0^{\circ}$ longitude per 6 hours $(4.8 \mathrm{~m}$ $\mathrm{s}^{-1}$ ). Model integration continues first until the average SST cooling under the storm core reaches quasi-steady state (i.e. $96 \mathrm{~h}$ for the $2.4 \mathrm{~m} \mathrm{~s}^{-1}$ experiments and $48 \mathrm{~h}$ for the $4.8 \mathrm{~m} \mathrm{~s}^{-1}$ experiments) and then continues further to allow for direct comparison with experiments that include a WCR, as discussed in section $3 b$.

\subsection{WCR Experiments}

In the experiments other than CTRL, a WCR is assimilated into the otherwise horizontallyhomogeneous ocean of CTRL using the feature-based methodology of Yablonsky and Ginis (2008). This WCR is nearly circular in shape, with a radius of $1.2^{\circ}$ (i.e. 133 $\mathrm{km}$ along the north-south axis and $123 \mathrm{~km}$ along the east-west axis), which is typical of WCRs in the Gulf of Mexico (e.g. Oey et al. 2005). The T profile at the center of the WCR is based on the $0-2500-m$ portion of the September GDEM climatological profile in the Caribbean Sea, except the upper ocean mixed layer temperature, and hence the SST, is adjusted slightly to match the upper ocean mixed layer temperature in the surrounding Gulf Common Water, thereby keeping the SST (but not the subsurface temperature) horizontallyhomogeneous in the assimilated field. Next, the 3D model is integrated for 96 hours without wind stress in the vicinity of the WCR, thereby allowing the density and current fields in the WCR to geostrophically adjust. The resulting vertical temperature cross-section is shown in Fig. 2a, and the $\mathrm{OHC}$ and ocean current vector field are shown in Fig. $2 \mathrm{~b}$, where the maximum ocean current velocity in the geostrophically-adjusted WCR is $1.9 \mathrm{~m} \mathrm{~s}^{-}$ 1. Note that the WCR does not experience beta drift because the ocean model is set on an f-plane. This ocean temperature field is then used to initialize both the 1D and 3D experiments, but the WCR's geostrophic currents are removed for the 1D experiments. Finally, the hurricane wind stress field translates due westward towards and then past a WCR centered at $85.7^{\circ} \mathrm{W}$ (allowing enough time for the average SST cooling under the storm core to first reach quasi-steady state, as in CTRL). Experiments are performed with the WCR located in the center of the storm track (WCRC), to the south (i.e. left) of the storm track (WCRL), and to the north (i.e. right) of the storm track (WCRR) (Fig. 3). Table 1 summarizes the important parameters for all experiments.

TABLE 1. Important parameters for all experiments.

\begin{tabular}{cccc}
\hline $\begin{array}{c}\text { Experiment } \\
\text { Name }\end{array}$ & $\begin{array}{c}\text { Ring } \\
\text { Location }\end{array}$ & $\begin{array}{c}\text { Translation } \\
\text { Speed }\end{array}$ & $\begin{array}{c}\text { Model } \\
\text { Dimensions }\end{array}$ \\
\hline CTRL-2.4-3D & None & $2.4 \mathrm{~m} \mathrm{~s}^{-1}$ & 3D \\
CTRL-2.4-1D & None & $2.4 \mathrm{~m} \mathrm{~s}^{-1}$ & 1D \\
CTRL-4.8-3D & None & $4.8 \mathrm{~m} \mathrm{~s}^{-1}$ & 3D \\
CTRL-4.8-1D & None & $4.8 \mathrm{~m} \mathrm{~s}^{-1}$ & 1D \\
WCRC-2.4-3D & Center & $2.4 \mathrm{~m} \mathrm{~s}^{-1}$ & 3D \\
WCRC-2.4-1D & Center & $2.4 \mathrm{~m} \mathrm{~s}^{-1}$ & 1D \\
WCRC-4.8-3D & Center & $4.8 \mathrm{~m} \mathrm{~s}^{-1}$ & 3D \\
WCRC-4.8-1D & Center & $4.8 \mathrm{~m} \mathrm{~s}^{-1}$ & 1D \\
WCRL-2.4-3D & Left & $2.4 \mathrm{~m} \mathrm{~s}^{-1}$ & 3D \\
WCRL-2.4-1D & Left & $2.4 \mathrm{~m} \mathrm{~s}^{-1}$ & 1D \\
WCRL-4.8-3D & Left & $4.8 \mathrm{~m} \mathrm{~s}^{-1}$ & 3D \\
WCRL-4.8-1D & Left & $4.8 \mathrm{~m} \mathrm{~s}^{-1}$ & 1D \\
WCRR-2.4-3D & Right & $2.4 \mathrm{~m} \mathrm{~s}^{-1}$ & 3D \\
WCRR-2.4-1D & Right & $2.4 \mathrm{~m} \mathrm{~s}^{-1}$ & 1D \\
WCRR-4.8-3D & Right & $4.8 \mathrm{~m} \mathrm{~s}^{-1}$ & 3D \\
WCRR-4.8-1D & Right & $4.8 \mathrm{~m} \mathrm{~s}^{-1}$ & 1D \\
\hline
\end{tabular}

\subsection{Averaging within the Storm Core}

Since the goal of this study is to quantify the magnitude of SST cooling only within the region providing most of the heat energy to the storm, the average SST cooling is calculated within a $60-\mathrm{km}$ radius around the storm center (hereafter dSST-60) and within a $200-\mathrm{km}$ radius around the storm center (hereafter dSST-200) while the storm-induced cooling is being influenced by the WCR (when present). Also, to understand the utility and potential shortcomings of preexisting $\mathrm{OHC}$ for predicting the average SST cooling, the area-averaged initial $\mathrm{OHC}$ along the storm track but prior to the storm's arrival is calculated (Fig. 4). The exact radius over which ocean heat flux significantly impacts storm intensity is not well known and likely varies depending on storm size, but $60-\mathrm{km}$ includes what may be considered the storm "inner-core" because it is $5-\mathrm{km}$ larger than the radius of maximum winds and is consistent with the inner-core definition of Cione and 
Uhlhorn (2003). Using a $200-\mathrm{km}$ radius captures what Cione and Uhlhorn (2003) define as the "inner-core wake", and idealized model sensitivity experiments performed by Shen et al. (2002) suggest that ocean heat flux may be important for storm intensity even at this large radius from the storm center.

\section{RESULTS AND DISCUSSION}

\subsection{Storm-core Sea Surface Cooling along the Storm Track}

dSST-60 for all experiments is shown in Fig. 5. Focusing first on only the CTRL experiments in each panel, it is evident that dSST-60 remains nearly constant as the storm translates westward from $\sim 300$ $\mathrm{km}$ east of the WCR's center longitude (present in all experiments except CTRL) to $\sim 300 \mathrm{~km}$ west of the WCR's center longitude, indicating that dSST-60 in all CTRL experiments is indeed in quasi-steady state in this region. Differences between CTRL-1D (Fig. 5a, c) and CTRL-3D (Fig. 5b, d) for both translation speeds are due entirely to the omission of upwelling in the former and the inclusion of upwelling in the latter (YG09). For CTRL-2.4, the difference between 1D (Fig. 5a) and 3D (Fig. $5 \mathrm{~b}$ ) is $>1{ }^{\circ} \mathrm{C}$, but for CTRL-4.8, the difference between 1D (Fig. 5c) and 3D (Fig. $5 \mathrm{~d}$ ) is only $\sim 0.1^{\circ} \mathrm{C}$. Hence, attempts here to extract the contribution of horizontal advection to SST cooling by comparing 1D and 3D experiments that include a WCR will be complicated by the significant impact of upwelling in the $2.4 \mathrm{~m} \mathrm{~s}^{-1}$ experiments, but not in the $4.8 \mathrm{~m} \mathrm{~s}^{-1}$ experiments.

Continuing with Fig. 5, the next step is to focus on the WCRC experiments. In all four WCRC experiments, the magnitude of dSST-60 generally decreases as the storm approaches the WCR and then increases towards its original value as the storm passes the WCR. This trend is consistent with the purely thermodynamic view of a WCR, whereby the deeper mixed layer within the WCR restricts the ability of the storm to entrain a significant quantity of cooler water into the upper oceanic mixed layer via shear-induced mixing. In other words, along the storm track, the WCRC 1D dSST-60 (Fig. 5a, c), 3D dSST-60 (Fig. 5b, d), and initial OHC (Fig. 4a) all generally have a similar trend. However, the reduction in the WCRC-3D dSST-60 is not quite symmetric over time, with a dampened reduction $\sim 100$ $\mathrm{km}$ before the storm reaches the WCR's center and slightly increased cooling relative to CTRL $\sim 250 \mathrm{~km}$ after the storm passes the WCR's center. It is difficult to ascertain exactly what causes these asymmetries, but one possibility is enhanced upwelling due to the additional surface current divergence induced by the interaction between the WCR's preexisting circulation and the hurricane-generated currents. More evidence for this enhanced upwelling process is presented in sections $3 b$ and $3 c$.

Perhaps the most significant result from Fig. 5 is the WCRR experiments. Consistent with the initially high $\mathrm{OHC}$ (Fig. 4a), the magnitude of the WCRR-1D dSST-60 decreases as the storm passes the WCR (Fig.
$5 a, c)$, but unlike WCRR-1D, the magnitude of the WCRR-3D dSST-60 increases dramatically as the storm passes the WCR (Fig. 5b, d). This increase in the magnitude of the WCRR-3D dSST-60 is caused by the WCR's anticyclonic circulation, which advects the storm's cold wake horizontally in the direction of the storm track, thereby increasing the SST cooling underneath the storm core. Similarly, although less dramatically, the magnitude of WCRL-3D dSST-60 (Fig. $5 b, d)$ decreases to a greater extent than the WCRL-1D dSST-60 (Fig. 5a, c) as the storm passes the WCR, suggesting that the WCR's circulation advects the storm's cold wake further behind the storm, thereby decreasing the SST cooling underneath the storm core. These cold wake advection processes associated with the presence of WCRs will be discussed in greater detail in sections $3 \mathrm{~b}$ and $3 \mathrm{c}$.

Finally, it is instructive to briefly consider dSST-200, primarily to examine if and how the dSST-200 trend differs from the dSST-60 trend as the storm traverses the WCR. In all 1D experiments that include a WCR, the dSST-200 (Fig. 6a, c) trend is similar to the dSST-60 trend (Fig. 5a, c), except the peak in dSST-200 magnitude reduction is further west (i.e. further past the WCR's center longitude) than the peak in dSST-60 magnitude reduction. In the $3 \mathrm{D}$ experiments, this westward shift in dSST-200 (Fig. 6b, d) relative to dSST-60 (Fig. 5b, d) is also evident. Perhaps most interesting, however, is the lack of significantly enhanced dSST-200 in WCRR-3D (Fig. 6b, d) as the storm center passes the WCR's center longitude, unlike the significant WCRR-3D dSST-60 enhancement that occurs in that region (Fig. $5 b, d$ ). In section $3 b$, it is shown that this lack of dSST-200 enhancement is due to cancellation during spatial averaging of positive and negative SST anomalies within the $200-\mathrm{km}$ radius circle.

\subsection{Spatial Structure of Sea Surface Cooling: WCRR - CTRL SST and Current Difference Fields}

Having examined dSST-60 and dSST-200 along the storm track for the various experiments, the next step is to examine the spatial structure of SST at specific times of interest for the experiments that yielded the most significant dSST-60 and dSST-200 results to try to determine the physical mechanism(s) for these results. Towards this end, Fig. 7 shows the SST and current vector difference field between WCRR and CTRL when the storm center is $\sim 50 \mathrm{~km}(\mathrm{a}, \mathrm{b}, \mathrm{c}, \mathrm{d})$ and $\sim 250-\mathrm{km}$ (e, f, g, h) past the WCR's center longitude. In the 1D experiments (Fig. 7a, c, e, g), the SST difference is positive within the WCR; this reduced cooling in WCRR relative to CTRL is caused by reduced shearinduced mixing and entrainment due to a deeper mixed layer within the WCR (Fig. 2). In the 3D experiments (Fig. $7 b, d, f, h$ ), however, the situation is more complex.

When the storm center is $\sim 50 \mathrm{~km}$ past the WCR's center longitude (Fig. 7b, d), the WCRR-3D cooling is reduced relative to CTRL-3D from the WCR's center towards its eastern periphery, but the WCRR-3D cooling is enhanced relative to CTRL-3D on the southern periphery of the WCR, that is, near the storm center. 
This sign change in the SST difference field northeast of the storm center (when the storm center is $\sim 50 \mathrm{~km}$ past the WCR's center longitude) explains why the difference in dSST-200 between WCRR-3D and CTRL-3D is smaller than the difference in dSST-60 (Figs. 5b, 5d, 6b, $6 d)$. The enhanced cooling near the storm center, especially in WCRR-2.4-3D (Fig. 7b), is caused by advection of the storm's cold wake westward along the storm track by the WCR's anticyclonic circulation, as indicated by the current vector difference field. Similarly, the WCR's circulation reduces cooling east of the WCR's center by advecting the cold wake southward toward the storm track.

When the storm center is $\sim 250 \mathrm{~km}$ past the WCR's center longitude (Fig. 7f, h), the WCRR-3D cooling is enhanced relative to CTRL-3D in two key regions. The first region of enhanced cooling is on the southern periphery (and in the $2.4 \mathrm{~m} \mathrm{~s}^{-1}$ experiment, also the western periphery) of the WCR, where the cold wake continues to be advected around the WCR. From a storm-core cooling perspective, however, this region is irrelevant because it is located far behind the storm center. For the $2.4 \mathrm{~m} \mathrm{~s}^{-1}$ experiment (Fig. 7f), the second region of enhanced cooling is located within the storm core, extending towards the north and east from the storm center. Since this second region is so far west of the WCR, advection is unlikely to be causing the enhanced cooling. Instead, enhanced upwelling is likely to be the cause, as evidenced by the divergent current difference vectors in the vicinity of the enhanced cooling. For the $4.8 \mathrm{~m} \mathrm{~s}^{-1}$ experiment (Fig. 7h), the second region of enhanced cooling is located further behind the storm core, consistent with the fact that maximum upwelling distance from the storm center increases with increasing storm translation speed (e.g. Ginis 2002; YG09).

\subsection{Spatial Structure of Sea Surface Cooling: SST and Surface Current Fields for All Experiments}

\subsubsection{STORM CENTER 50 KM PAST WCR'S CENTER LONGITUDE}

While the difference fields discussed in section $3 \mathrm{~b}$ highlight the most significant results, it is instructive to examine the actual SST and surface current fields in each experiment when the storm center is $\sim 50 \mathrm{~km}$ past the WCR's center longitude (Figs. 8 and 9). Focusing first on CTRL (Figs. $8 \mathrm{~g}, 8 \mathrm{~h}, 9 \mathrm{~g}$, and 9h), the most notable feature is the cold wake, which along with the surface current vectors is generally maximized to the right of the storm track. As discussed by Price (1981), the rightward bias in the surface current field is caused by the superposition of the wind stress vector's rotation due to the storm's forward motion, inertial rotation due to the Coriolis force, and to a lesser extent, the asymmetry in the wind stress magnitude; the rightward bias in the SST cooling is a result of the rightward bias in the shear-induced turbulent mixing in the water column. The cold wake in the CTRL-3D experiments (Figs. 8h and 9h) is colder than in the corresponding CTRL-1D experiments (Figs. $8 \mathrm{~g}$ and $9 \mathrm{~g}$ ); this difference is due to the inclusion of upwelling in the former but not the latter (e.g. Price 1981; YG09). However, significant SST differences between CTRL-1D and CTRL-3D within the storm core is limited to the CTRL-2.4 experiments (Fig. 8g, h); in the CTRL-4.8 experiments (Fig. 9g, h), upwelling is much weaker and occurs too far behind the storm center to significantly impact the storm-core SST (as in YG09).

In the 1D experiments with a WCR (Figs. 8a, 8c, $8 e, 9 a, 9 c$, and $9 e$ ), the shape and position of the cold wake are identical to the CTRL experiments (Figs. $8 \mathrm{~g}$ and $9 \mathrm{~g}$ ), except where the deeper mixed layer (Fig. 2a) and higher $\mathrm{OHC}$ (Fig. 2b) within the WCR restricts the SST cooling, consistent with the purely thermodynamic view of a WCR. By examining the 3D experiments with a WCR (Figs. 8b, 8d, 8f, 9b, 9d, and 9f), however, the impact of advection becomes clear. In WCRC-3D, WCRL-3D, and WCRR-3D, the cold wake is shifted (relative to CTRL) towards the south, east, and west, respectively, due to the anticyclonic circulation around the WCR. This cold wake shift has little impact within the storm core in WCRC-3D (Figs. 8b and 9b), but in WCRL-3D, the cold wake is advected backwards (i.e. out of the storm core) (Figs. 8d and 9d), while in WCRR$3 \mathrm{D}$, the cold wake is advected forwards (i.e. into the storm core) (Figs. 8f and 9f), consistent with the difference fields discussed in section $3 \mathrm{~b}$. Also, while qualitatively similar, the relative impact of advection into or out of the storm core is greater for the $2.4 \mathrm{~m} \mathrm{~s}^{-1}$ experiments (Fig. 8) than for the $4.8 \mathrm{~m} \mathrm{~s}^{-1}$ experiments (Fig. 9) because $2.4 \mathrm{~m} \mathrm{~s}^{-1}$ is closer than $4.8 \mathrm{~m} \mathrm{~s}^{-1}$ to the WCR's maximum circulation velocity $\left(1.9 \mathrm{~m} \mathrm{~s}^{-1}\right)$.

\subsubsection{STORM CENTER 250 KM PAST WCR'S CENTER LONGITUDE}

The next step is to examine the SST and surface current fields in the 3D experiments when the storm center is $\sim 250 \mathrm{~km}$ past the WCR's center longitude (Fig. 10). While the continued advection of the cold wake around the WCR is easily apparent, the more important feature from a storm-core perspective is the enhanced cooling north and east of (but near) the storm center in the WCRC (Fig. 10a, b) and WCRR (Fig. 10e, f) experiments relative to the CTRL experiments (Fig. 10g, $\mathrm{h}$ ), leading to an increase of the dSST-60 magnitude (Fig. 5b, d). Thus, the presence of a WCR may enhance storm-core SST cooling not only when the WCR is in the immediate vicinity of the storm, but also when the WCR is at a larger distance from the storm.

Given that this enhanced cooling exists in WCRC and WCRR, the final step is to determine the most likely cause, which is hypothesized to be enhanced upwelling. Enhanced upwelling occurs if the current divergence is increased, but the strong near-inertial signal in the surface current vectors makes increased current divergence difficult to observe. Therefore, it is instructive to examine the temperature and current vector fields in the $3 \mathrm{D}$ experiments at $125-\mathrm{m}$ depth (Fig. 11), which is below the region of vertical mixing. At this depth, the temperature anomalies are caused primarily by the hurricane-generated near-inertial internal waves 
and non-oscillatory upwelling along the track. Note that upwelling and the associated geostrophic currents are much stronger in CTRL-2.4-3D (Fig. 11g) than in CTRL4.8-3D (Fig. 11h). In WCRC-2.4-3D (Fig. 11a) and WCRR-2.4-3D (Fig. 11e), the WCR's circulation causes the increased temperature anomalies north and east of the storm center, suggesting that the enhanced SST cooling observed there is due to enhanced upwelling. A similar, albeit much weaker, effect is observed in the WCRC-4.8-3D (Fig. 11b) and WCRR-4.8-3D (Fig. 11f) experiments. Finally, it should be noted that the WCR's circulation in WCRL-2.4-3D (Fig. 11c) and WCRL-4.83D (Fig. 11d) has no influence on upwelling in the storm-core area, thereby explaining the WCR's negligible impact on the storm-core SST cooling.

\section{SUMMARY AND CONCLUSIONS}

A WCR's anticyclonic circulation is typically neglected as a contributing factor for hurricane intensity change. Here, it is shown that this anticyclonic circulation may have a significant impact on the location and magnitude of hurricane-induced sea surface cooling. Contrary to the result expected when considering $\mathrm{OHC}$ alone, advection of the hurricaneinduced cold wake by a WCR's circulation, when the WCR is located to the right of the storm track, can cause increased sea surface cooling under the storm core relative to the case where no WCR is present, thereby creating a less favorable condition for hurricane intensification. In addition, the WCR's circulation can increase divergence in the surface layer currents, thereby enhancing upwelling and storm-core SST cooling, even well after the storm center has passed the WCR.

It is worth mentioning that the results presented here may be sensitive to properties of both the hurricane and the WCR that are not tested here. For example, changing the radius of maximum winds, the inflow angle of the surface winds, or the latitude of the storm center would change the wind stress vector rotation rate relative to the local inertial period; hence, the distance of maximum upwelling from the storm center and the rightward bias and magnitude of the cold wake would change even for the same storm translation speed. A WCR with a faster (slower) circulation velocity would be expected to advect the cold wake more (less) in the same amount of time. Also, a WCR on the right side of the storm track that is larger (smaller), but with the same circulation velocity, could advect the cold wake along the storm track for a longer (shorter) amount of time.

For future study, the concepts presented here could be extended to a hurricane propagating along an oceanic front, such as the Gulf Stream, Kuroshio, or one of the branches of the Loop Current. Similarly, experiments could be run with a cyclonically-rotating cold core ring (CCR) instead of a WCR, and it would not be surprising if a CCR located to the right of the storm track created a more favorable condition for hurricane intensification by advecting the hurricane-induced cold wake further behind the storm core, thereby decreasing the SST cooling within the storm core. Perhaps a more important next step, however, is to rerun experiments similar to the ones presented here but with a coupled hurricane-ocean model. The clear advantage of coupled model experiments is that the impact of the WCR's circulation on hurricane intensity could be directly evaluated instead of inferring the intensity change based on storm-core SST cooling; the disadvantage, however, is that the experimental design would be less constrained because the surface wind stress will change as the hurricane intensity changes, and the storm track and translation speed could not be prescribed a priori.

\section{ACKNOWLEDGEMENTS}

The authors wish to thank Drs. Biju Thomas and Yalin Fan for assistance with the Princeton Ocean model. We also thank Carlos Lozano (NOAA/NCEP/EMC/MMAB) for constructive comments. Finally, we thank the reviewers for their contribution to this manuscript. This research was funded by NOAA grant NOAA4400080656, awarded to the Graduate School of Oceanography at URI. This document was recently submitted to Monthly Weather Review and is currently in review.

\section{REFERENCES}

Bender, M. A., I. Ginis, R. Tuleya, B. Thomas, and T. Marchok, 2007: The operational GFDL Coupled Hurricane-Ocean Prediction System and a summary of its performance. Mon. Wea. Rev., 135, 3965-3989.

Blumberg, A. F., and G. L. Mellor, 1987: A description of a three-dimensional coastal ocean circulation model. Three-Dimensional Coastal Ocean Models. N. Heaps, Ed., Vol. 4, Amer. Geophys. Union, 1-16.

Cione, J. J., and E. W. Uhlhorn, 2003: Sea surface temperature variability in hurricanes: Implications with respect to intensity change. Mon. Wea. Rev., 131, 1783-1796.

D'Asaro, E. A., T. B. Sanford, P. P. Niiler, and E. J. Terrill, 2007: Cold wake of Hurricane Frances. Geophys. Res. Lett., 34, L15609, doi:10.1029/2007GL030160.

Emanuel, K., 2003: Tropical cyclones. Ann. Rev. Earth Planet. Sci., 31, 75-104.

Ginis I., 1995: Interaction of tropical cyclones with the ocean. Global Perspectives on Tropical Cyclones, Ch. 5, R. L. Elsberry, Ed., Tech. Doc. WMO/TD No. 693, World Meteorological Organization, Geneva, Switzerland, 198-260.

Ginis, I., 2002: Tropical cyclone-ocean interactions. Atmosphere-Ocean Interactions, Advances in Fluid Mechanics Series, No. 33, WIT Press, 83-114.

Holland, G. J., 1980: An analytic model of the wind and pressure profiles in hurricanes. Mon. Wea. Rev., 108, 1212-1218.

Leipper, D., and D. Volgenau, 1972: Hurricane heat potential of the Gulf of Mexico. J. Phys. Oceanogr., $2,218-224$. 
Lin, I.-I., C.-C. Wu, I.-F. Pun, and D.-S. Ko, 2008: Upper ocean thermal structure and the western North Pacific category-5 typhoons. Part I: Ocean features and category-5 typhoon's intensification. Mon. Wea. Rev., 136, 3288-3306.

Mainelli M., M. DeMaria, L. K. Shay, and G. Goni, 2008: Application of oceanic heat content estimation to operational forecasting of recent Atlantic category 5 hurricanes. Wea. Forecasting, 23, 3-16.

Mellor, G. L., 2004: Users guide for a three-dimensional, primitive equation, numerical ocean model (June 2004 version). Prog. in Atmos. and Ocean. Sci, Princeton University, $56 \mathrm{pp}$.

Moon, I.-J., I. Ginis, T. Hara, and B. Thomas, 2007: A physics-based parameterization of air-sea momentum flux at high wind speeds and its impact on hurricane intensity predictions. Mon. Wea. Rev., 135, 2869-2878.

Oey, L.-Y., T. Ezer, and H.-C. Lee, 2005: Loop Current, rings, and related circulation in the Gulf of Mexico: A review of numerical models and future challenges. Circulation in the Gulf of Mexico: Observations and Models, Geophys. Monogr., Vol. 161, Amer. Geophys. Union, 31-56.

Price, J., 1981: Upper ocean response to a hurricane. J. Phys. Oceanogr., 11, 153-175.

Shay, L. K., G. J. Goni, and P. G. Black, 2000: Effects of a warm oceanic feature on Hurricane Opal. Mon. Wea. Rev., 128, 1366-1383.
Shen, W., and I. Ginis, 2003: Effects of surface heat flux-induced sea surface temperature changes on tropical cyclone intensity. Geophys. Res. Lett., 30, 1933, doi:10.1029/2003GL017878.

Shen, W., I. Ginis, and R. E. Tuleya, 2002: A numerical investigation of land surface water on landfalling hurricanes. J. Atmos. Sci., 59, 789-802.

Teague, W. J, M. J. Carron, and P. J. Hogan, 1990: A comparison between the Generalized Digital Environmental Model and Levitus climatologies. J. Geophys. Res., 95, 7167-7183.

Tung, C.-A., 2008: Impact of reduced air sea momentum flux on hurricane and wave modeling. M.S. thesis, Graduate School of Oceanography, University of Rhode Island, $69 \mathrm{pp}$. [Available from Graduate School of Oceanography, University of Rhode Island, South Ferry Road, Narragansett, RI 02882.]

Yablonsky, R. M., and I. Ginis, 2008: Improving the ocean initialization of coupled hurricane-ocean models using feature-based data assimilation. Mon. Wea. Rev., 136, 2592-2607.

Yablonsky, R. M., and I. Ginis, 2009: Limitation of onedimensional ocean models for coupled hurricaneocean model forecasts. Mon. Wea. Rev., 137, in review. 
a

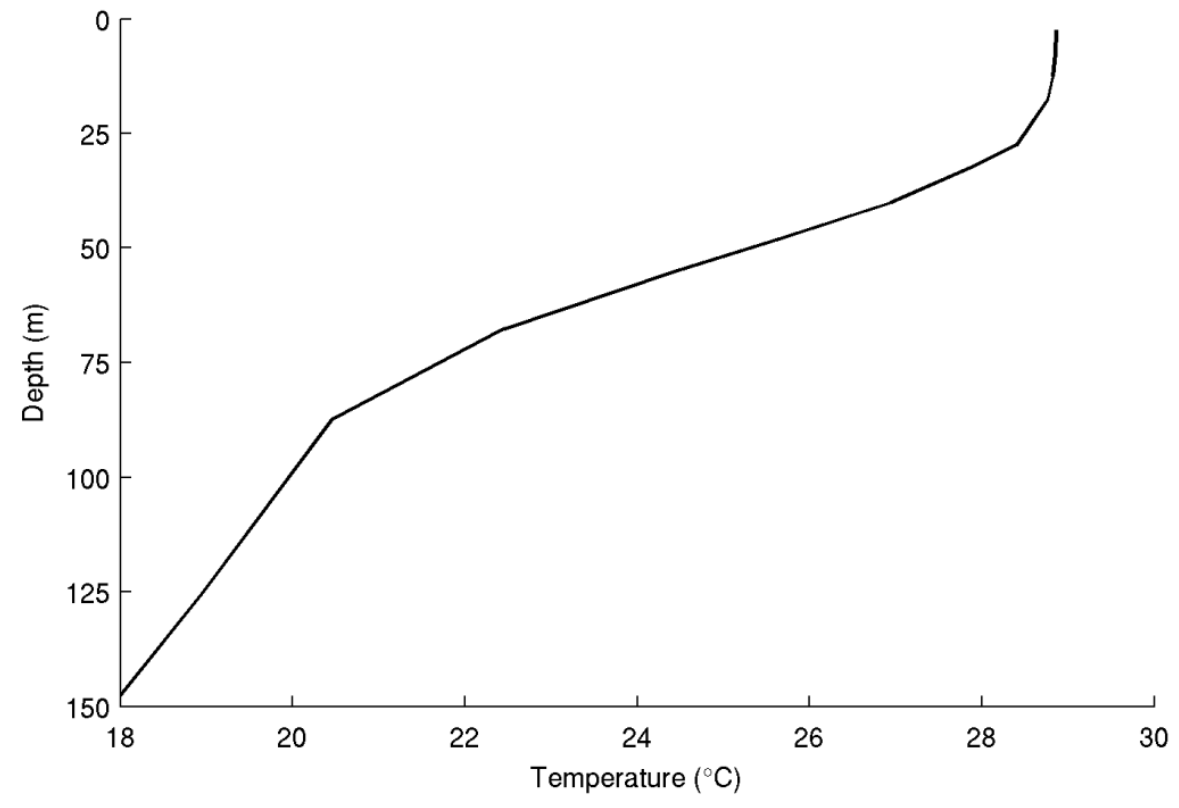

b

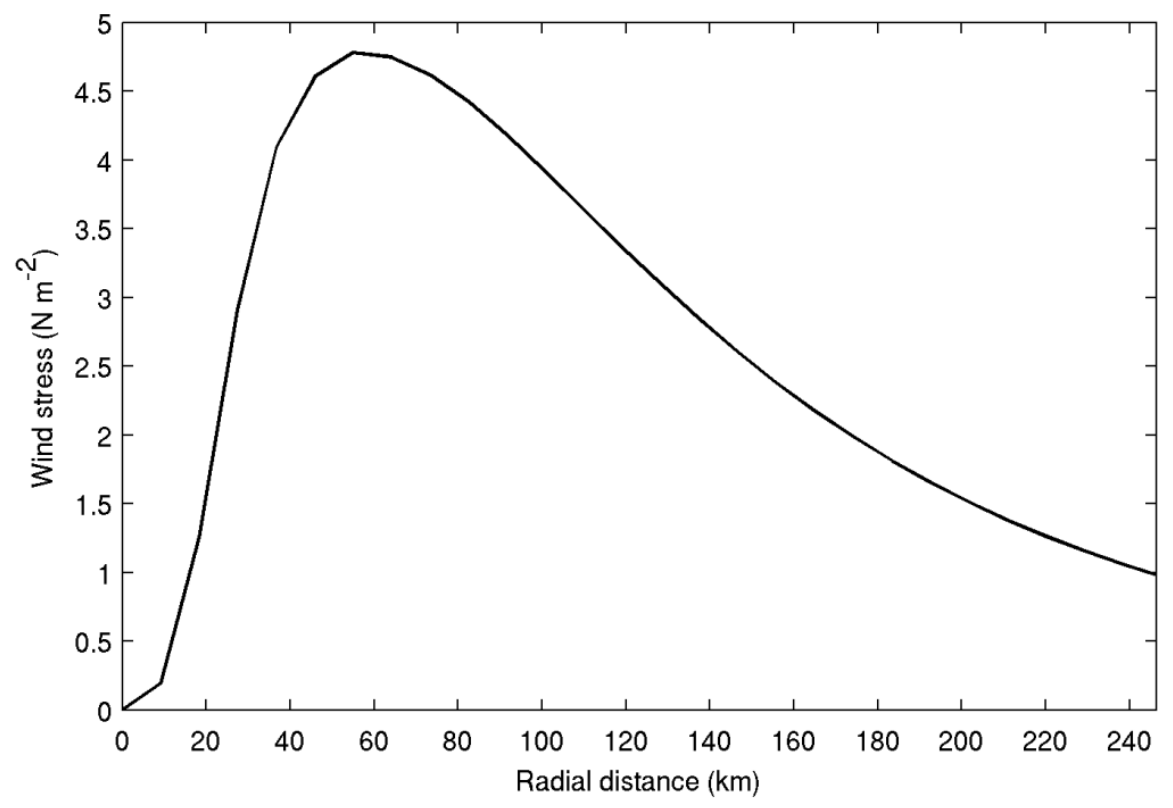

FIG. 1. (a) Upper $150 \mathrm{~m}$ of initial ocean temperature $\left({ }^{\circ} \mathrm{C}\right)$ profile in CTRL; (b) axisymmetric radial profile of surface wind stress $\left(\mathrm{N} \mathrm{m}^{-2}\right)$. 

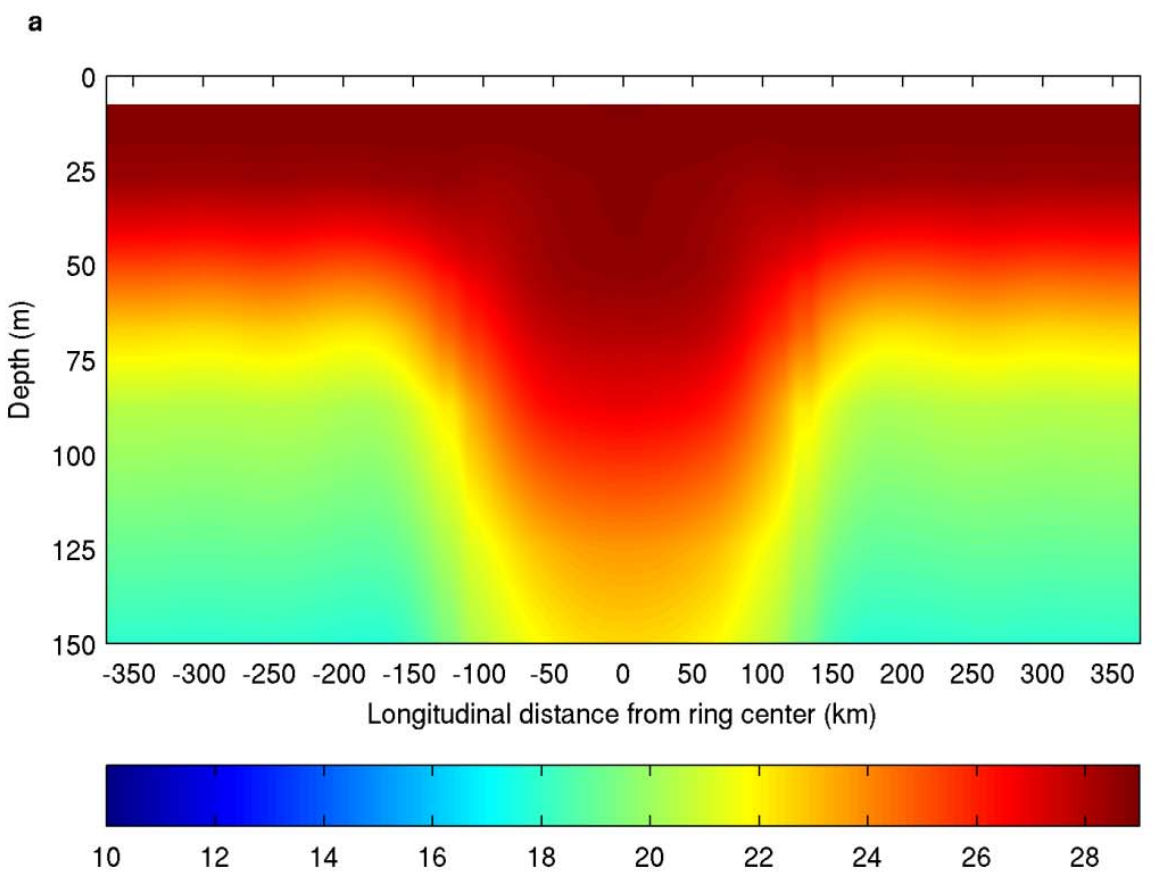

b
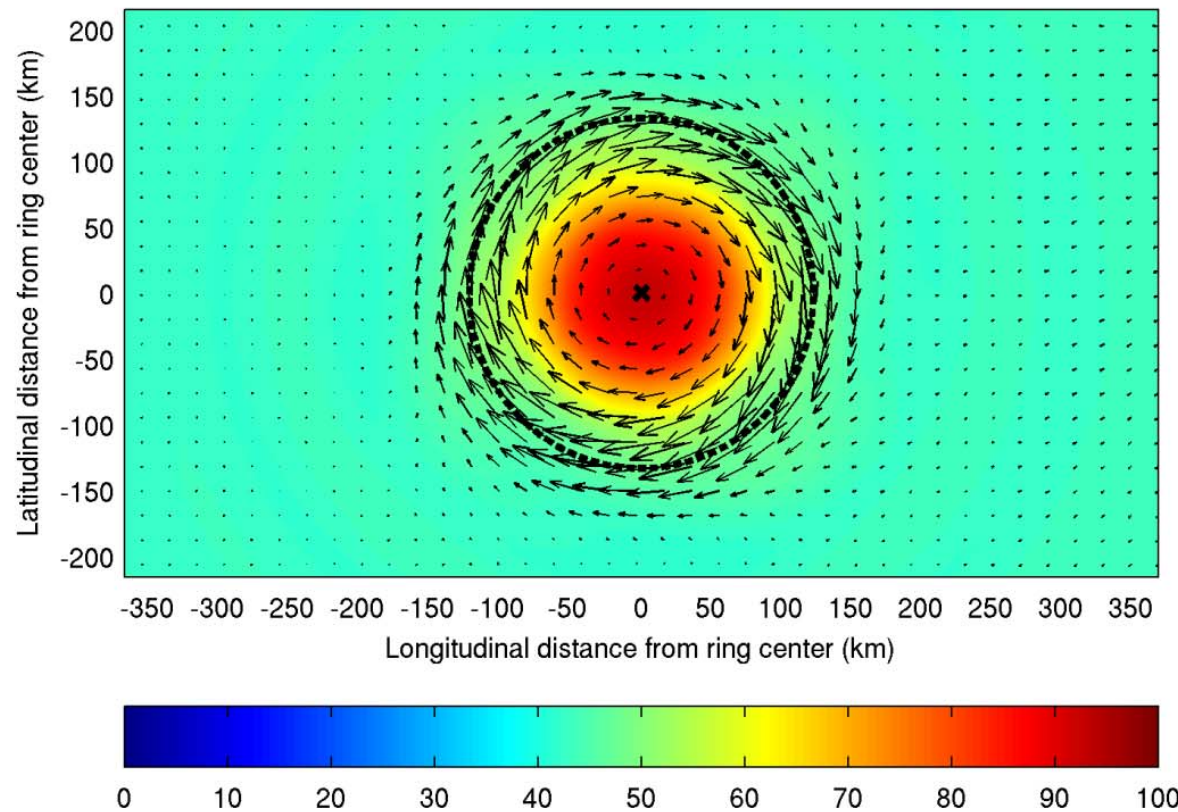

FIG. 2. (a) Ocean temperature $\left({ }^{\circ} \mathrm{C}\right)$ cross-section through the undisturbed WCR and (b) $\mathrm{OHC}\left(\mathrm{kJ} \mathrm{cm}^{-2}\right)$ and surface current vectors (3D simulations only) in and around the undisturbed WCR; the WCR's perimeter is indicated by the dashed circle. 


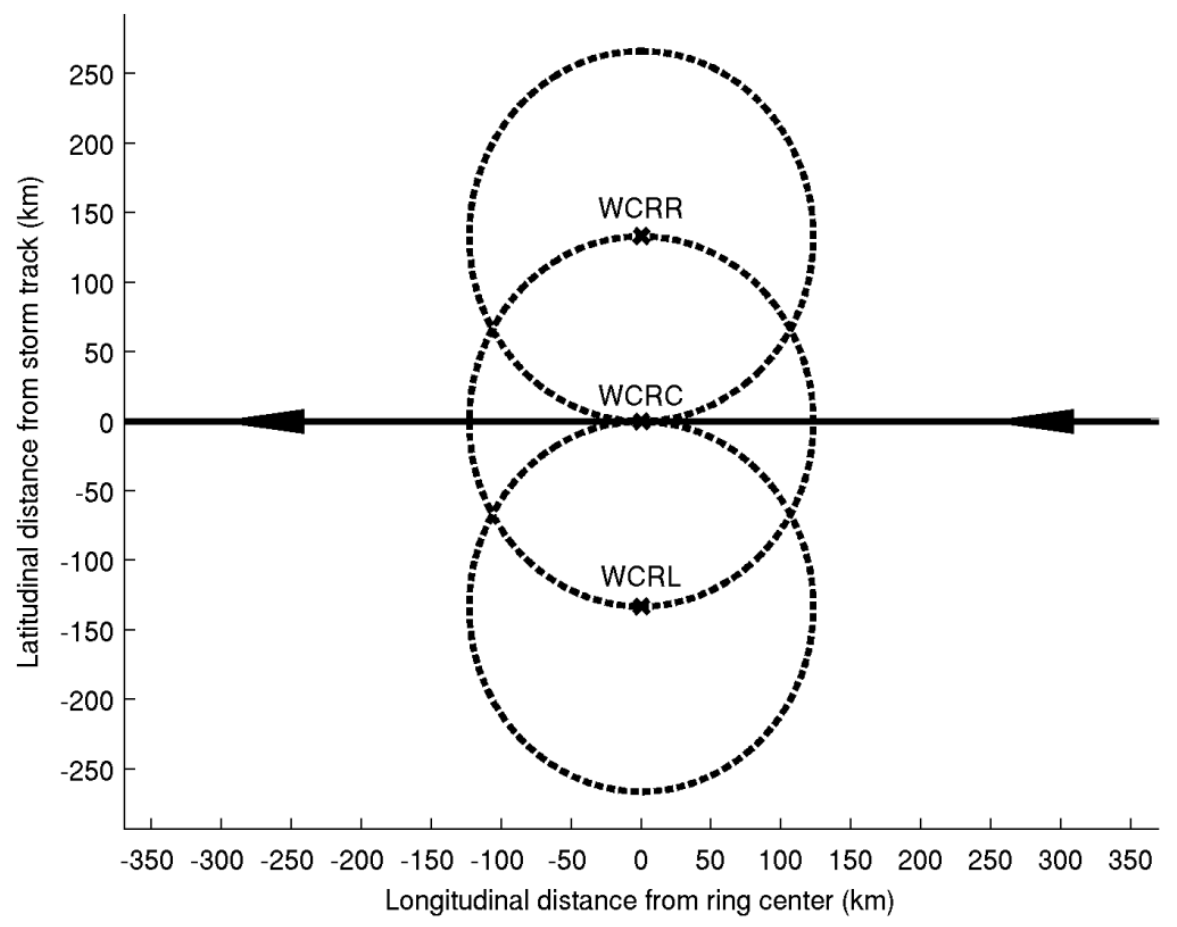

FIG. 3. Schematic indicating the WCR position when located in the center of the storm track (WCRC), to the south (i.e. left) of the storm track (WCRL), and to the north (i.e. right) of the storm track (WCRR). Storm track and direction are indicated by the horizontal line with embedded, westward-pointing arrows. 

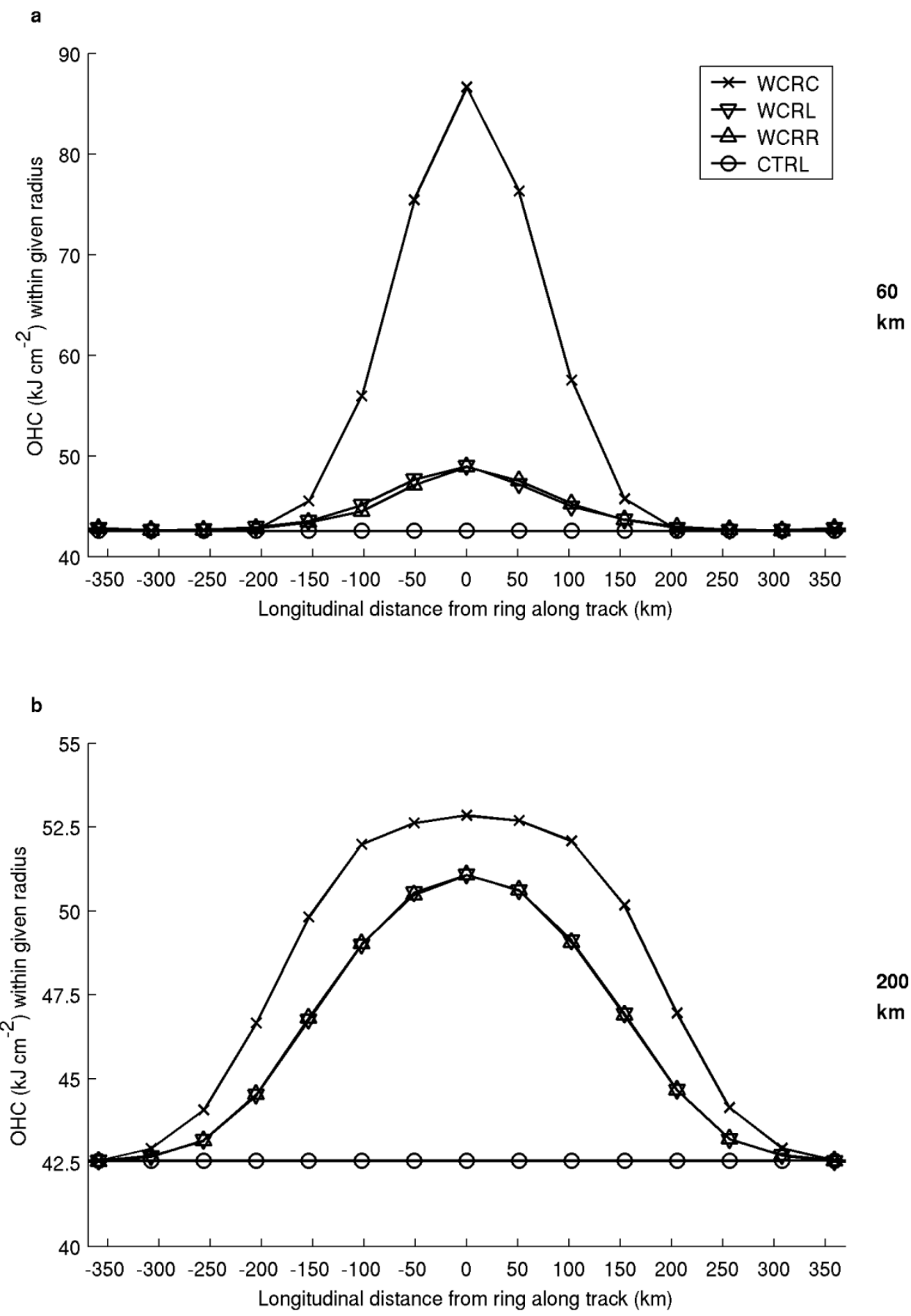

FIG. 4. Average initial $\mathrm{OHC}\left(\mathrm{kJ} \mathrm{cm}^{-2}\right)$ within (a) $60-\mathrm{km}$ radius and (b) 200-km radius around various points along the storm's future track. Each panel includes WCRC ("x"), WCRL (downward triangle), WCRR (upward triangle), and CTRL ("o") experiments. 
a

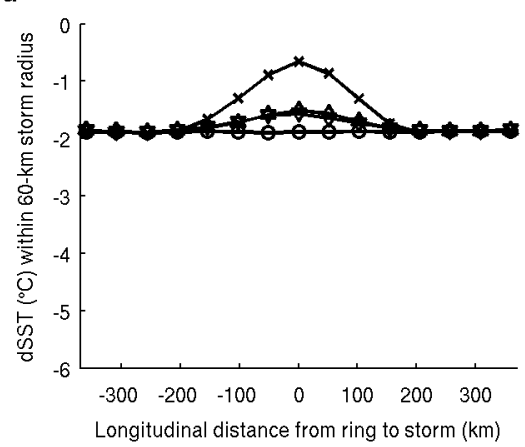

c

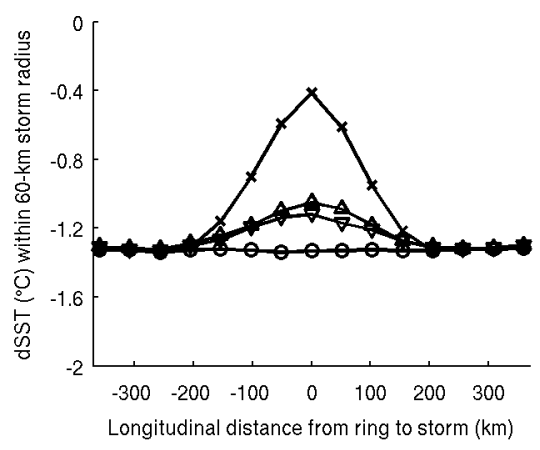

3D

b
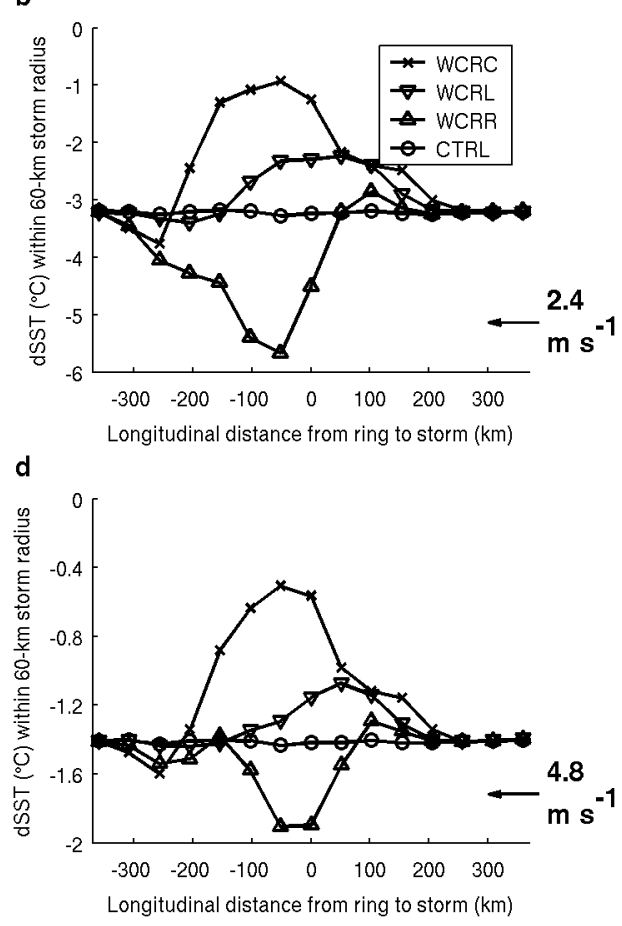

FIG. 5. Average SST cooling within a 60-km radius of the storm center (dSST-60) for the 1D (a, c) and 3D (b, d) experiments with translation speeds of $2.4 \mathrm{~m} \mathrm{~s}^{-1}(\mathrm{a}, \mathrm{b})$ and $4.8 \mathrm{~m} \mathrm{~s}^{-1}$. Each panel includes WCRC ("x"), WCRL (downward triangle), WCRR (upward triangle), and CTRL ("o") experiments. 

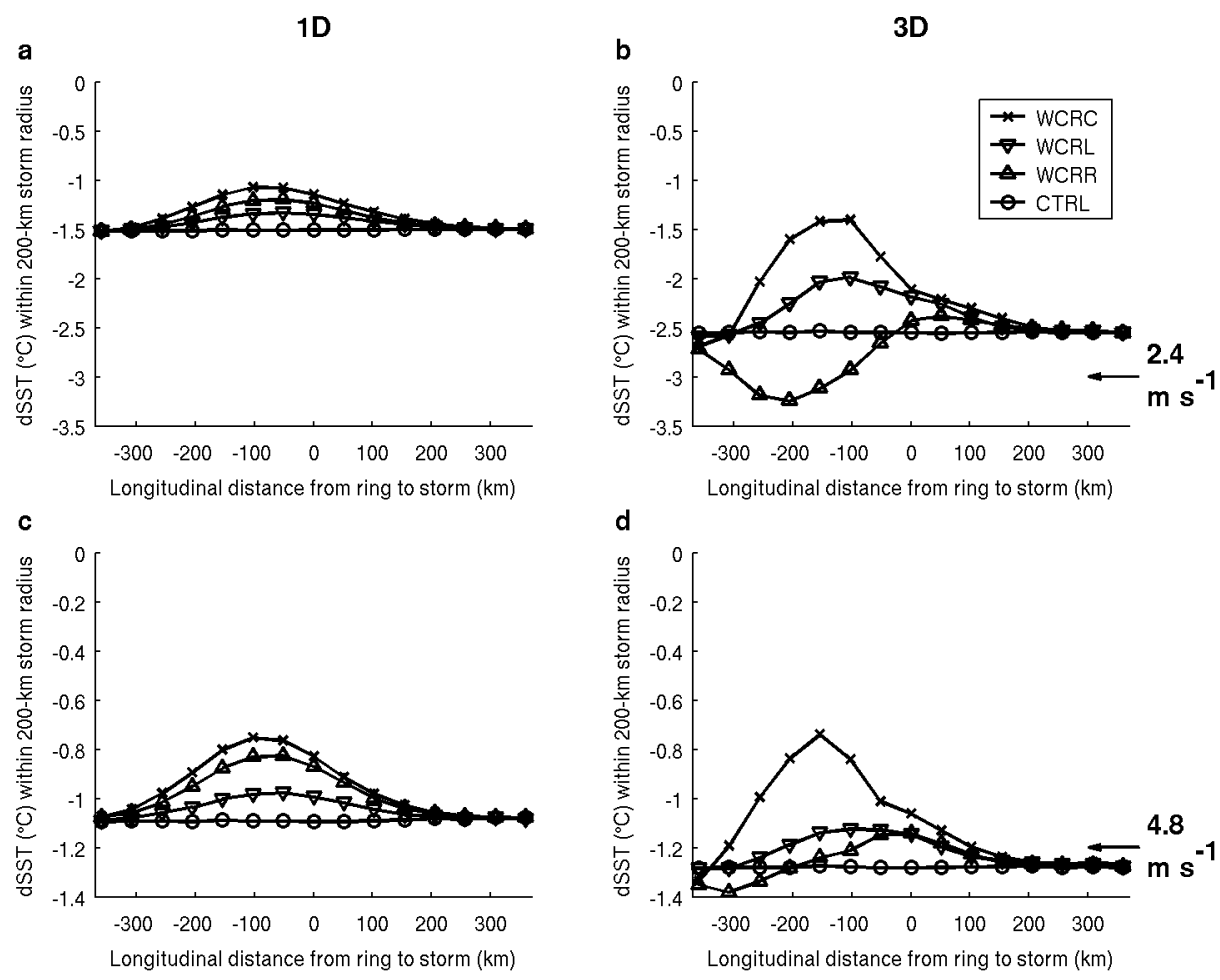

FIG. 6. Same as Fig. 5 but within a 200-km radius of the storm center (dSST-200). 
1D
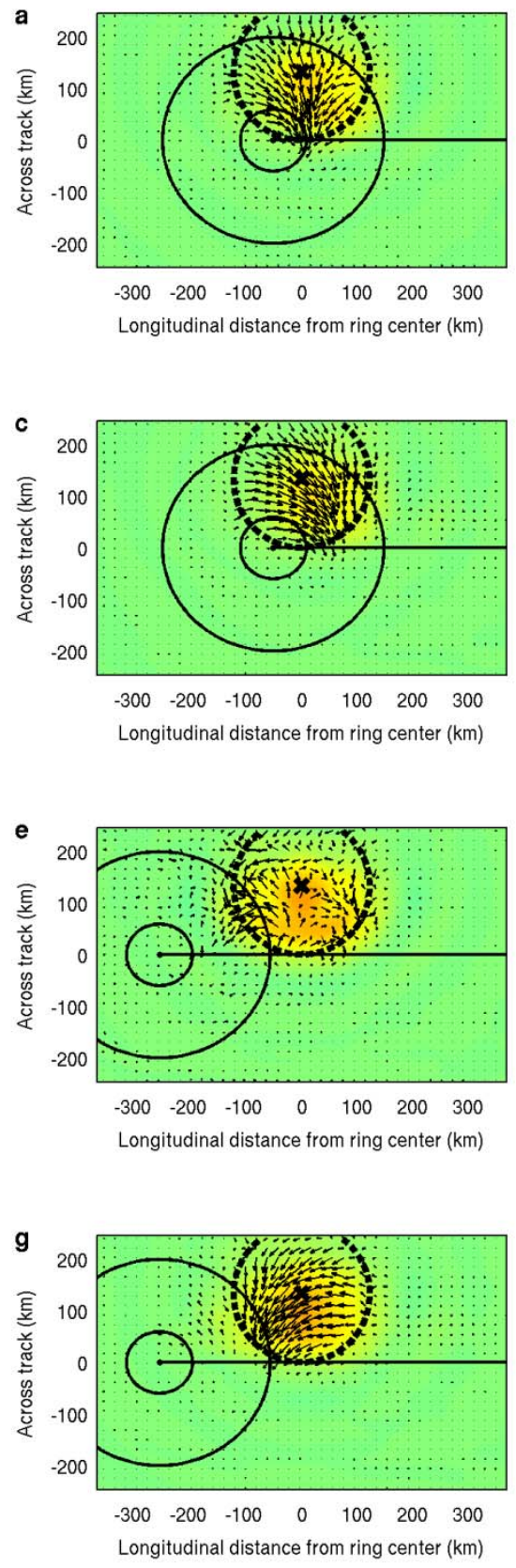

3D

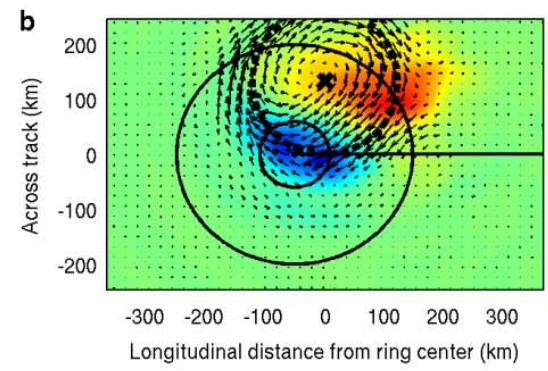

2.4

$\mathrm{m} \mathrm{s}^{-1}$

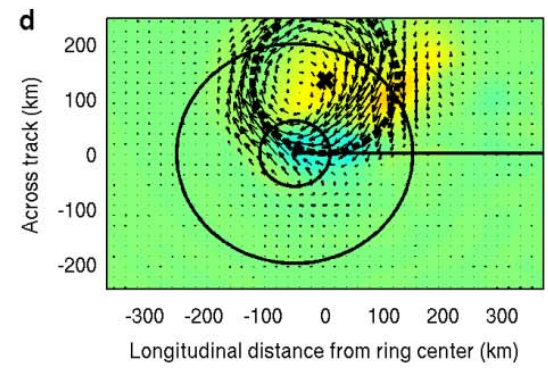

4.8

$\mathrm{m} \mathrm{s}^{-1}$

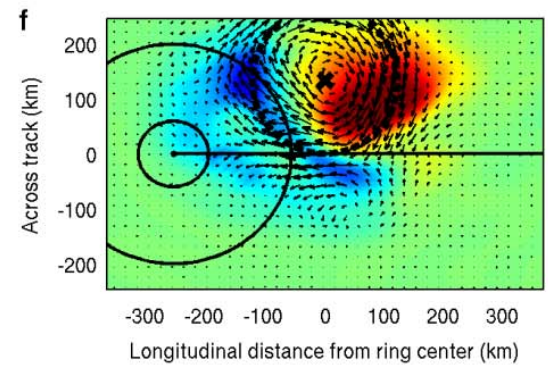

2.4

$\mathrm{m} \mathrm{s}^{-1}$

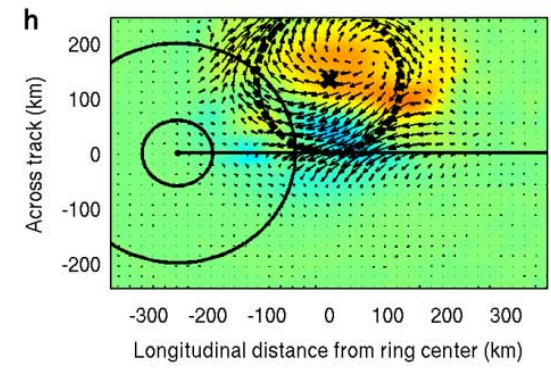

4.8

$\mathrm{m} \mathrm{s}^{-1}$

FIG. 7. WCRR - CTRL SST $\left({ }^{\circ} \mathrm{C}\right)$ and surface current vector difference field when storm center is $\sim 50 \mathrm{~km}(\mathrm{a}, \mathrm{b}, \mathrm{c}, \mathrm{d})$ and $250 \mathrm{~km}(\mathrm{e}, \mathrm{f}, \mathrm{g}, \mathrm{h})$ past the WCR's center longitude for the 2.4-1D (a, e), 2.4-3D (b, f), 4.8-1D (c, g), and 4.8-3D $(\mathrm{d}, \mathrm{h})$ experiments. Thin solid circles indicate $60-\mathrm{km}$ and $200-\mathrm{km}$ radii from the storm center; thick dashed circle indicates the WCR's perimeter. 
1D
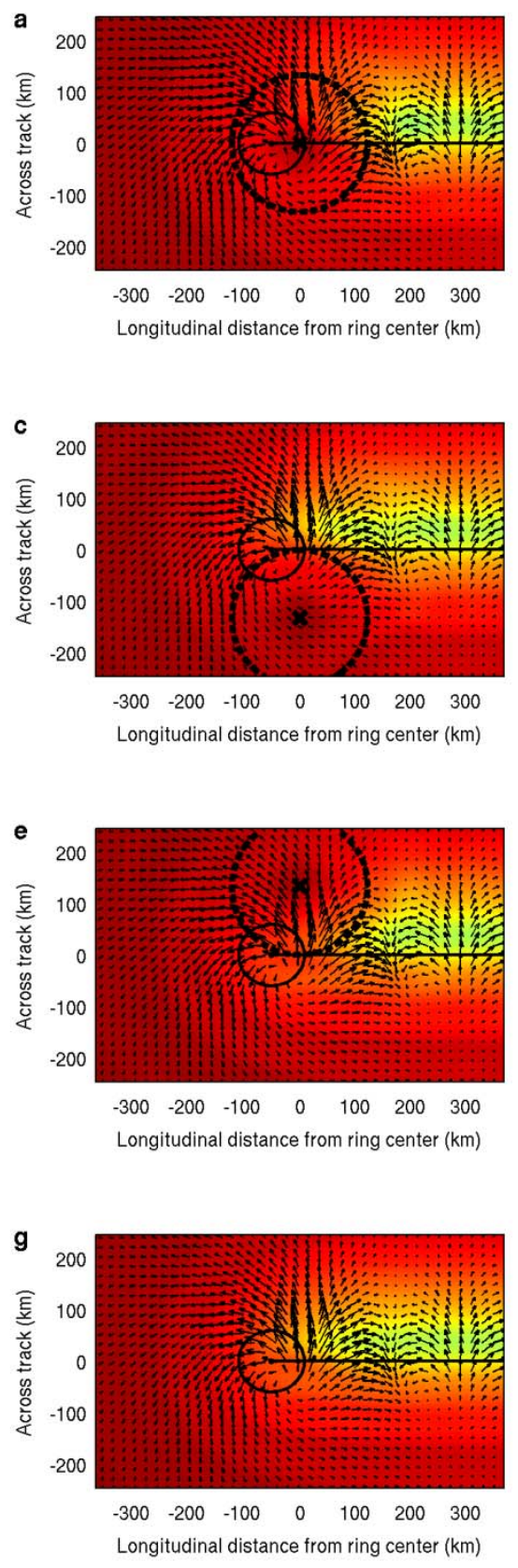

3D
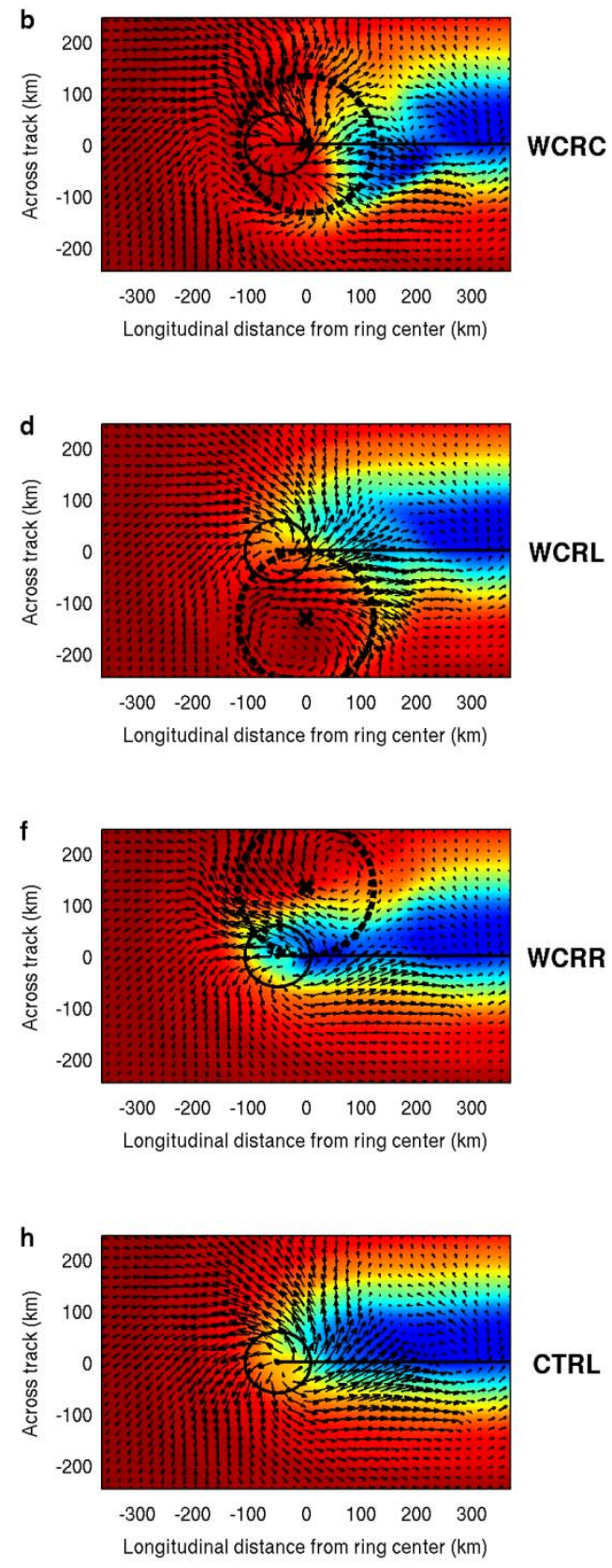

CTRL

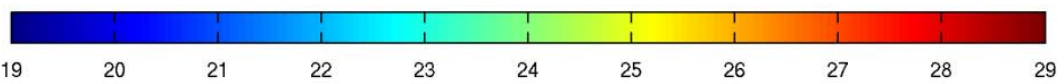

FIG. 8. SST $\left({ }^{\circ} \mathrm{C}\right)$ and surface current vectors when storm center is $\sim 50 \mathrm{~km}$ past the WCR's center longitude for (a) WCRC-2.4-1D, (b) WCRC-2.4-3D, (c) WCRL-2.4-1D, (d) WCRL-2.4-3D, (e) WCRR-2.4-1D, (f) WCRR-2.4-3D, (g) CTRL-2.4-1D, and (h) CTRL-2.4-3D. Circles are as in Fig. 7 except 200-km radius is omitted. 
1D
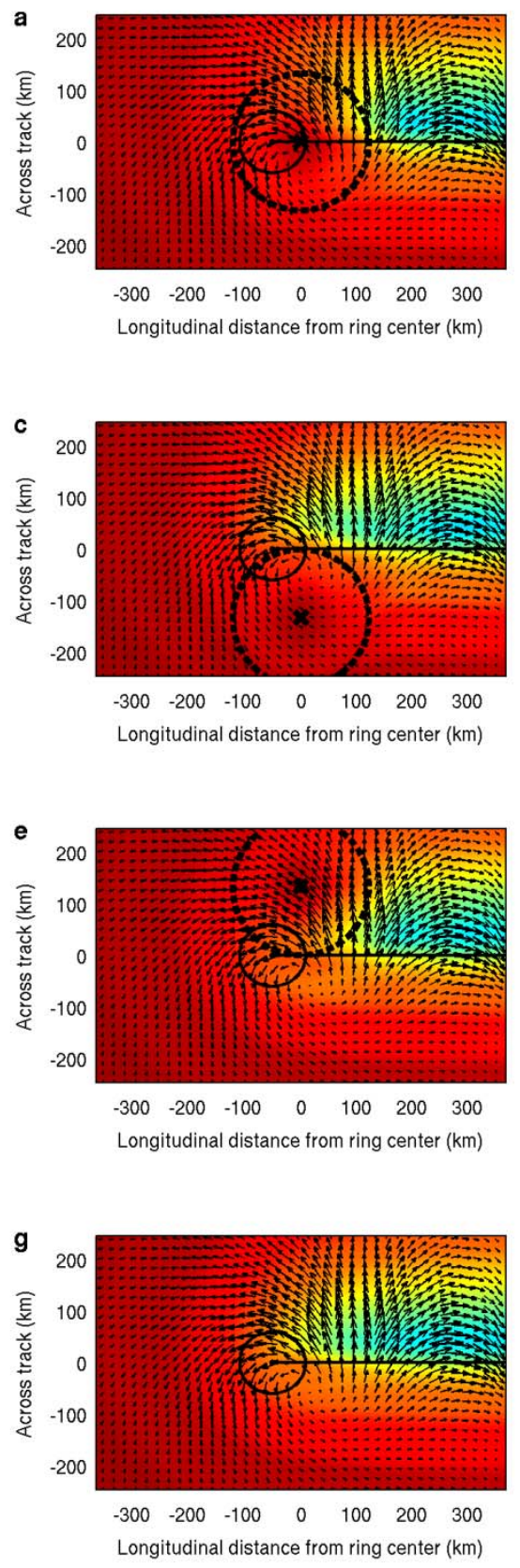

3D
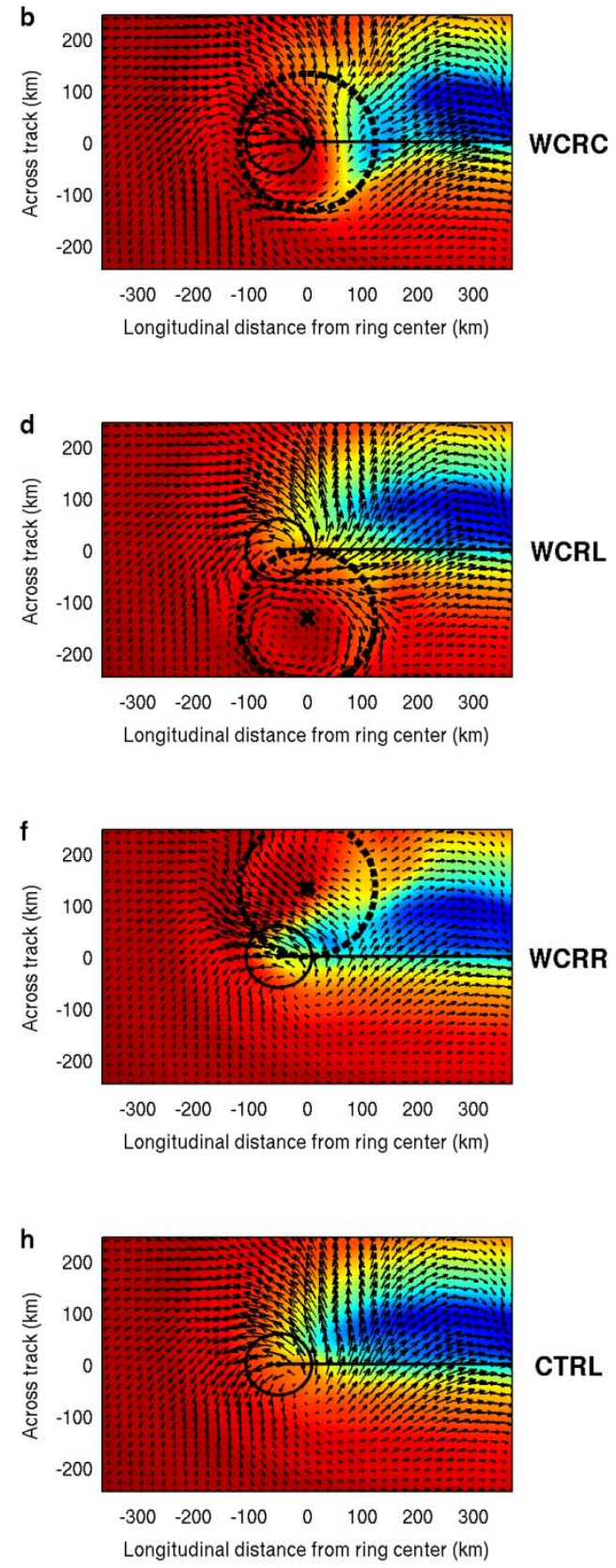

28

FIG. 9. Same as Fig. 8 but for $4.8 \mathrm{~m} \mathrm{~s}^{-1}$ instead of $2.4 \mathrm{~m} \mathrm{~s}^{-1}$ translation speed. 

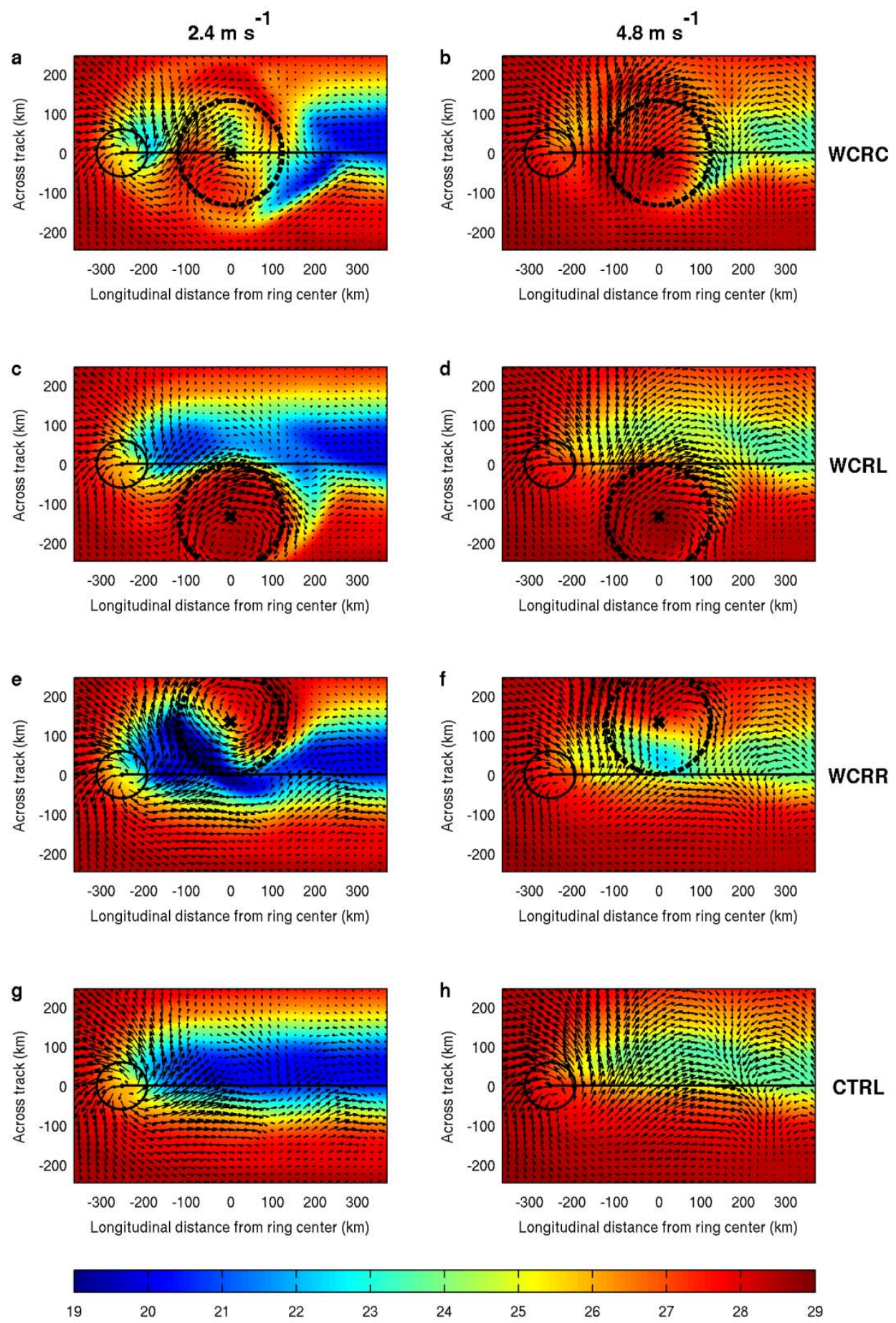

FIG. 10. SST $\left({ }^{\circ} \mathrm{C}\right)$ and surface current vectors when storm center is $\sim 250 \mathrm{~km}$ past the WCR's center longitude for (a) WCRC-2.4-3D, (b) WCRC-4.8-3D, (c) WCRL-2.4-3D, (d) WCRL-4.8-3D, (e) WCRR-2.4-3D, (f) WCRR-4.8-3D, (g) CTRL-2.4-3D, and (h) CTRL-4.8-3D. Circles are as in Fig. 8. 

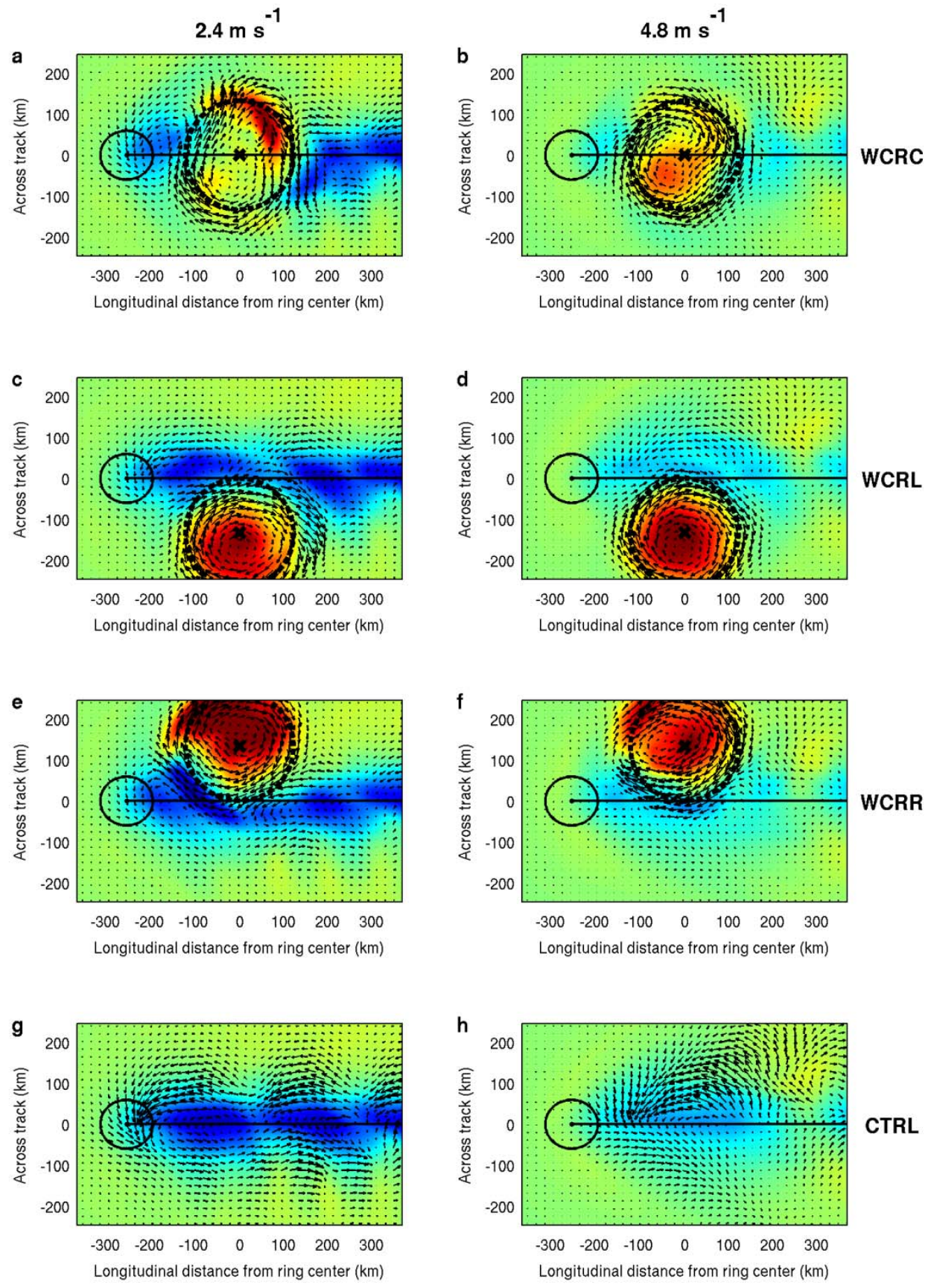

CTRL

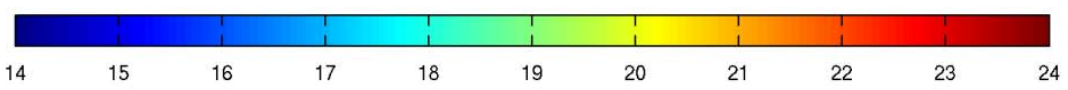

FIG. 11. Same as Fig. 10 but at 125-m depth instead of the sea surface. 